\title{
Variation of measured cross- sectional cell dimensions and calculated water vapor permeability across a single growth ring of spruce wood
}

\author{
Journal Article \\ Author(s): \\ Derome, Dominique; Zillig, Wolfgang; Carmeliet, Jan \\ Publication date: \\ 2012-09 \\ Permanent link: \\ https://doi.org/10.3929/ethz-b-000054610
}

Rights / license:

In Copyright - Non-Commercial Use Permitted

Originally published in:

Wood Science and Technology 46(5), https://doi.org/10.1007/s00226-011-0445-8 


\title{
Variation of measured cross-sectional cell dimensions and calculated water vapor permeability across a single growth ring of spruce wood
}

\author{
Dominique Derome $\cdot$ Wolfgang Zillig $\cdot$ Jan Carmeliet
}

Received: 30 July 2010/Published online: 19 October 2011

(C) Springer-Verlag 2011

\begin{abstract}
A statistical study of the cell dimensions in a growth ring of spruce along the radial and tangential directions is performed. The data are used to study the variation of the cell vapor permeability in the growth ring. Studying cell rows within one growth ring, the frequency distributions of the cell wall thickness in the radial direction and of the lumen dimension in the tangential direction are found to be both unimodal. In contrast, the frequency distributions of these dimensions in the other directions are bimodal, where the different modes can be attributed to earlywood and latewood. Analysis of the bimodal distributions results in the determination of threshold values of cell wall thickness and the lumen dimension for earlywood and latewood tracheids. The cell dimensions are used to predict cell porosity and water vapor permeability distribution within a growth ring. The bimodal frequency distributions of the tangential cell wall thickness and the radial lumen dimension provide an explanation for the observed bimodal frequency distribution of the cell water vapor permeability both in radial and in tangential directions. Contrary to measured macroscopic vapor permeability results, the tracheid geometry results in lower cell vapor permeability in radial than in tangential direction. This confirms that rays play an important role in the vapor permeability of
\end{abstract}

\footnotetext{
D. Derome $(\bowtie)$

Fluids and porous materials, EMPA, Überlandstrasse 129, 8600 Dübendorf, Switzerland e-mail: dominique.derome@empa.ch
}

W. Zillig

Fraunhofer-Institut für Bauphysik, Fraunhoferstraße 10, 83626 Valley, Germany

\section{J. Carmeliet}

Chair of Building Physics, Swiss Federal Institute of Technology ETHZ, ETH-Hönggerberg, 8093 Zürich, Switzerland

\section{J. Carmeliet}

Laboratory for Building Science and Technology, Empa, Swiss Federal Laboratories for Materials Testing and Research, Überlandstrasse 129, 8600 Dübendorf, Switzerland 
wood, as they can be considered as pathways for vapor transport in radial direction. The dataset analyzed in this paper leads to a set of parameters characterizing the earlywood and latewood cell dimensions. Such characterization can be used, for example, for producing synthetic data for computational modeling studies.

\section{Introduction}

In softwoods, like spruce, the growth ring consists mainly of longitudinal tracheid cells varying in size from earlywood to latewood and, in less proportion of about $5 \%$ in volume, of ray cells oriented in the radial direction. The cross section shape of the tracheids, approximately rectangular, can vary significantly in cell wall width and in lumen area over one growth ring. Such variations render dimension determination quite labor-intensive. However, as the wood cellular structure highly influences wood material properties, e.g. density, mechanical properties, and transport properties such as water vapor permeability, the measurement and analysis of cell dimensions are important. Several works have attempted to simplify or reduce the labor involvement of cell measurements. Reme and Helle (2002) and Sarén et al. (2001) describe automated recognition procedures for analyzing transverse cell dimensions, using scanning electron microscopy (SEM) images and light microscopy images, respectively. However, these procedures still have not been developed sufficiently to adequately distinguish certain features, like pits and rays, or assign the prevailing direction, radial and tangential, of a measured length. Thus, highly time-consuming, manual dimensioning on high-resolution images still provides an accuracy not achieved by automated approaches.

Dimensions of tracheids have been studied since the nineteenth century. Brändström (2001) has reviewed the main results of the last 50 years for Norway spruce. Recent works include Reme and Helle (2002) on cell wall thickness of Norway spruce and Scots pine, without differentiation of directions, and Sarén et al. (2001) on earlywood of Norway spruce. Often, average dimensions and standard deviations are reported for the cell length or diameter and for cell wall thickness, with differentiation between earlywood and latewood. Little work reports on variations of these parameters in the radial and tangential directions. Variations of the dimensions within a single growth ring are rarely specified beyond mean and standard deviation. Reme and Helle (2002) show that the frequency distribution of the radial diameter of the tracheid cells in different growth rings in spruce has a slight bimodal distribution with a positive skew. The same shape of distribution is seen for the earlywood cell wall thickness in the radial direction (Sarén et al. 2001). Partitioning one growth ring in 13 slices, Eder et al. (2009) report for each slice the average areas of cell walls and lumens in the radial direction. However, a more complete description of the variation of cell dimension variations within one single spruce growth ring and the analysis and impact of this variation on cell properties is not yet available.

The cell geometry, using either the actual cellular layout or synthetic or average dimensions, has been used in many instances to calculate material properties, like density, permeability (e.g., Badel and Perré 2003), mechanical properties (Badel and Perré 2007, Hofstetter et al. 2005, Qing and Mishnaevsky 2009), and even 
deformation and fracturing (Holmberg et al. 1999), using different computational techniques. These studies use either a microscopic image of a limited number of cells or average dimensions, often taken from literature. Studies of such type would benefit from guidelines on the appropriate quantification of the cell geometry to be used in modeling studies.

The objective of this study is to characterize in detail the cell dimensions in one single growth ring of Norway spruce (Picea abies (L.) Karst.). The cell dimensions are then used for the prediction of material properties within this growth ring, namely cell porosity and cell water vapor permeability. The paper is organized as follows. First, the method for determining the cell dimensions is presented, followed by the second part with presentation and analysis including calculation of porosity and discussion of the dimensioning results. In the third part, as an application example, the obtained cell dimensions are used to determine the variation of the cell vapor permeability in a single growth ring. The study is limited to transverse directions; thus, the variation of cell geometry in longitudinal direction is not studied in this paper. Using a scanning electron microscopy (SEM) image acquired on dry wood, this study does not include effects of geometry variations resulting from moisture adsorption.

\section{Materials and methods}

The specimen studied is taken from a heartwood plank of Norway spruce (Picea abies (L.) Karst.). A board of approximately $1 \mathrm{~cm} \times 8 \mathrm{~cm}$ is cut out of the plank after a first pre-drying period. The density profile across the board determined by X-ray projection, see Fig. 1, shows that the minimum and maximum densities and the proportion of earlywood and latewood are comparable in successive growth rings of this board, indicating that the growth rings of this series are of similar configuration. The board is then sliced to provide the sample for the (SEM) study. The sample is dried in vacuum and then coated with gold. The SEM image used for this study, selected based on its clarity, shows a single growth ring, as presented in Fig. 2a. The exact distance between the studied growth ring and the pith is not known but certainly does not include juvenile wood. The image is calibrated by a scale bar on the original SEM image. The resolution of the image is 1,440 pixel per $\mathrm{mm}$, which is sufficient for the smallest features to be measured, like the thin walls of earlywood cells.

The cellular dimensioning is performed directly from the SEM image. The measurements are taken manually on ten continuous cell rows, indicated by arrows in Fig. 2a. In total, the dimensions of 808 individual cells are determined.

\section{Normalized ring position of cells}

The average growth ring width is determined by measuring the distance between the growth ring borders along the cell rows in the SEM image. The average width is $3,078 \mu \mathrm{m}$ with a standard deviation of $11 \mu \mathrm{m}$. As the growth ring width varies for each cell row in the SEM image, the measurements that follow are reported in terms of a normalized position of the cell within the growth ring. The middle lamella between the last latewood cell and the first earlywood cell is defined as the growth 


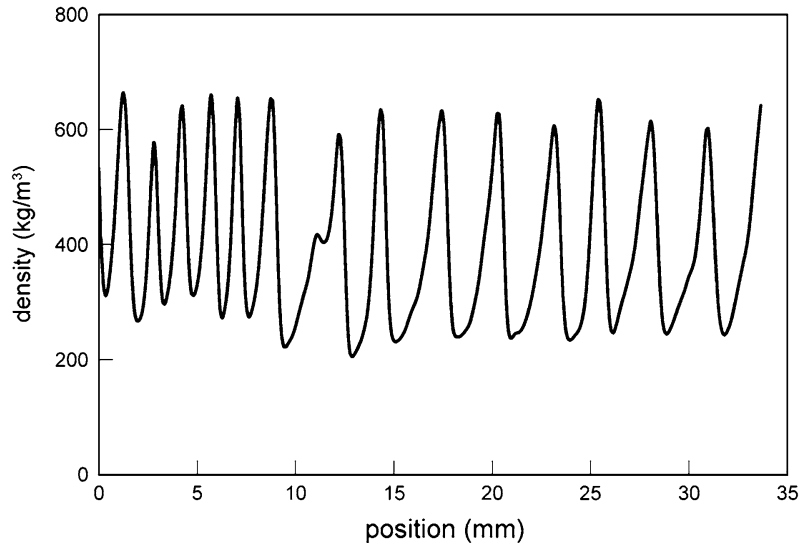

Fig. 1 Density profile across several growth rings measured by X-ray projection

(a)

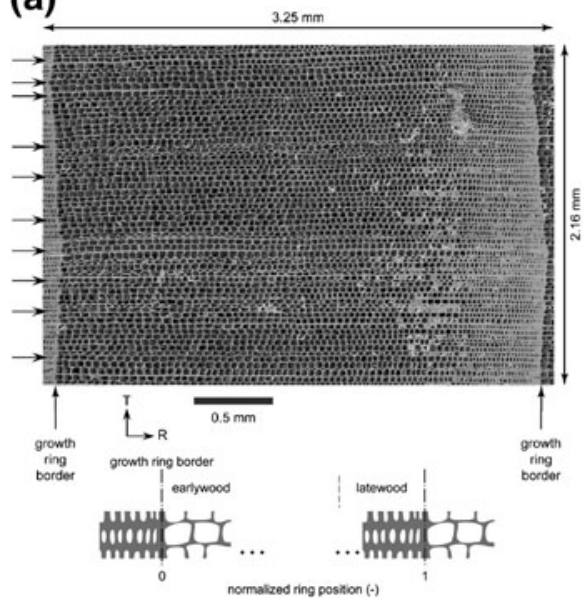

(b)

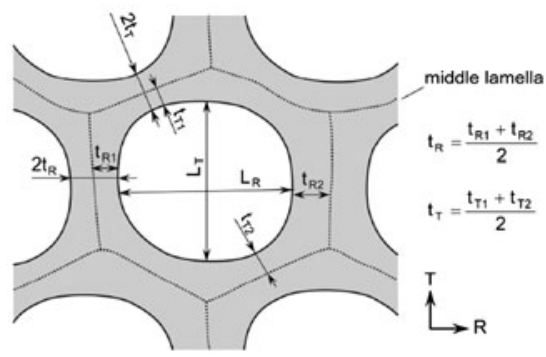

Fig. 2 a SEM image of transverse section of the growth ring of spruce wood used for determination of cell dimensions. The arrows indicate the ten cell rows studied. Below, identification of the start $(0)$ and end (1) of the cell row used to normalize the cell position within one row, b Dimensioning schemes used for cell wall thickness and lumen dimensions in the radial and tangential directions

ring border, designated with vertical dashed line, as shown in Fig. 2a. The relative position of the cell to the growth ring border is determined by taking the distance of the cell center to the growth ring border and dividing it by the growth ring total width for this cell row. Thus, a normalized ring position of 0 marks the start of the growth ring and of 1 , the end of the cell row.

\section{Definitions of dimensions}

The following dimensions are measured: wall thickness in radial, $t_{R}$, and in tangential, $t_{T}$, directions and lumen length in radial, $L_{R}$, and tangential, $L_{T}$, 
directions. Figure $2 \mathrm{~b}$ illustrates how each dimension is defined, given the natural irregularity of the cell layout.

Regarding the determination of cell wall thickness, it is taken into account that the individual cells are not perfectly aligned and the middle lamella that separates the cells is not always recognizable on the SEM image. Therefore, the total distances between two adjacent lumens $\left(2 t_{R}\right.$ and $\left.2 t_{T}\right)$ are measured. Assuming that the middle lamella divides the cell wall in layers of the same thickness, the single wall thickness is therefore determined to be half of the double cell wall thickness. Then, the cell wall thickness for each cell is defined as the average of two single cell wall thicknesses measured on both sides of the cell center, for each direction.

For the determination of the lumen dimensions, cell walls and cell lumens of the SEM image are marked manually in black and white, respectively. Although wood tracheids are often modeled as rectangles with rounded corners, cross sections of cells often show diverse and more complex configurations. Here, the software ImageJ is used to determine best-fitting ellipses through each individual lumen. The calculated dimensions of the major and minor axes of the best fitting ellipse are attributed to the dimensions, $L_{R}$ and $L_{T}$, of the lumen accordingly.

The study of cell dimensions is limited to a single growth ring, partly due to the highly time-consuming dimensioning method. The growth ring studied here has been selected from different SEM images to be representative for the chosen wood board. Variation between different growth rings at different positions in wood was observed. However, the focus of this paper is on a single growth ring since a detailed study, not yet reported in literature, can lead to valuable information and a better fundamental understanding of the variation in cell properties over growth rings.

\section{Results and analysis}

In this section, a statistical study on the cell dimensions as determined for 808 cells in one growth ring is presented. The data are statistically analyzed by a sum of shifted Weibull distribution functions. The cumulative distribution is given by

$$
F_{X}(x)=\sum_{i=1}^{n} f_{i}\left(1-\exp \left(-\left(\frac{x-\varepsilon_{i}}{u_{i}-\varepsilon_{i}}\right)^{k_{i}}\right)\right), \quad \sum_{i=1}^{n} f_{i}=1
$$

with $n$ the modality or number of distributions, $f_{i}$ a weight factor, $k_{i}$ a shape parameter, $u_{i}$ a scale parameter and $\varepsilon_{i}$ the location parameter indicating the shift of the distribution.

Cell wall thickness distributions in radial and tangential directions

Figure $3 \mathrm{a}, \mathrm{b}$ presents the cell wall thickness in radial and tangential directions as a function of the normalized ring position. The cell wall thickness $t_{R}$ in the radial direction remains almost constant across the growth ring and slightly increases toward the end of the growth ring. The cell wall thickness $t_{T}$ in tangential direction 
remains quite constant over the earlywood region and increases strongly in the latewood region. As shown later, the latewood is situated approximately above a relative ring position of 0.8 . Both thicknesses show scatter over the total growth ring. The scatter is especially high in earlywood for radial direction and in latewood for tangential direction.

Looking at the frequency distributions of the cell wall thickness in radial and tangential directions (Fig. 4a), a skewed unimodal distribution for the thickness in radial direction can be seen. The distribution of the cell wall thickness in tangential direction is clearly bimodal, where the first mode represents earlywood and is rather symmetric and the second mode is attributed to latewood and is rather skewed. Table 1 gives the mean values and standard deviations. In radial direction, the mean wall thickness is $3.6 \mu \mathrm{m}$, while, in tangential direction, the wall thickness is $2.1 \mu \mathrm{m}$ in earlywood and $4.4 \mu \mathrm{m}$ in latewood.

The observed bimodal distribution in tangential direction is in accordance with the results presented by Reme and Helle (2002). However, in this analysis, the cell wall thickness is measured independently of the direction. In terms of average values, the cell walls in tangential direction have almost the same values of $2.90 \mu \mathrm{m}$ for earlywood and $4.69 \mu \mathrm{m}$ for latewood as found by Ollinmaa (1961 cited in Brändström 2001). However, in the radial direction, Ollinmaa observed a thicker

(a)

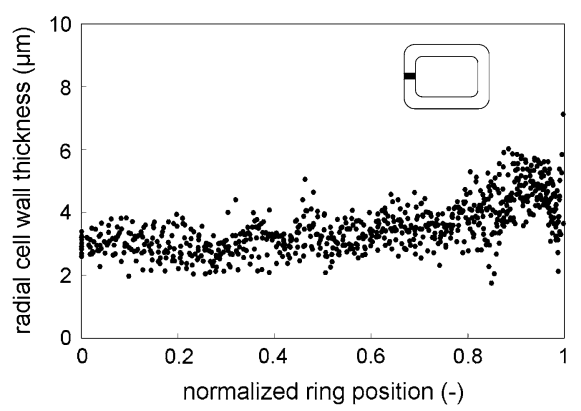

(c)

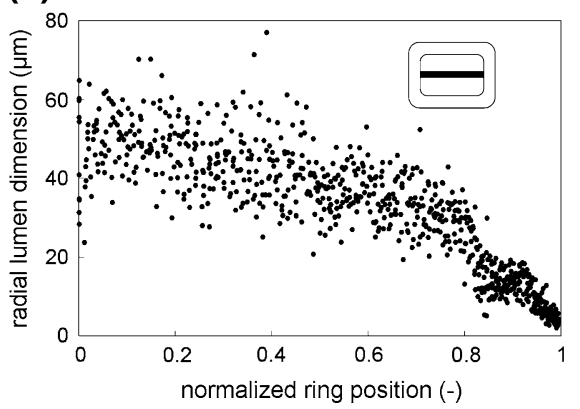

(b)

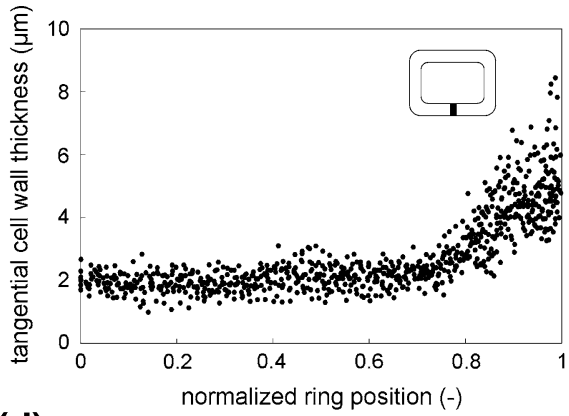

(d)

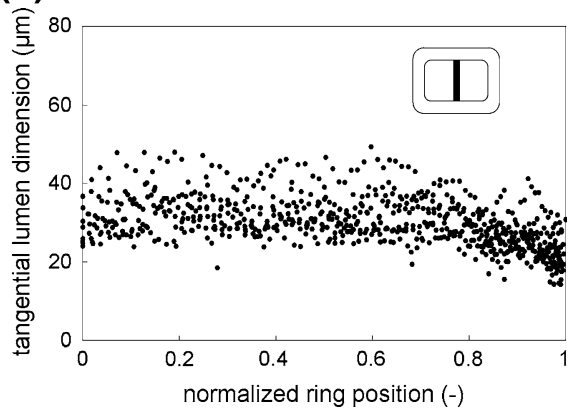

Fig. 3 Graphs of four measured dimensions versus normalized ring position, a cell wall thickness in radial direction, $t_{R}$; $\mathbf{b}$ cell wall thickness in tangential direction, $t_{T}$; $\mathbf{c}$ lumen dimension in radial direction, $L_{R} ; \mathbf{d}$ lumen dimension in tangential direction, $L_{T}$ 

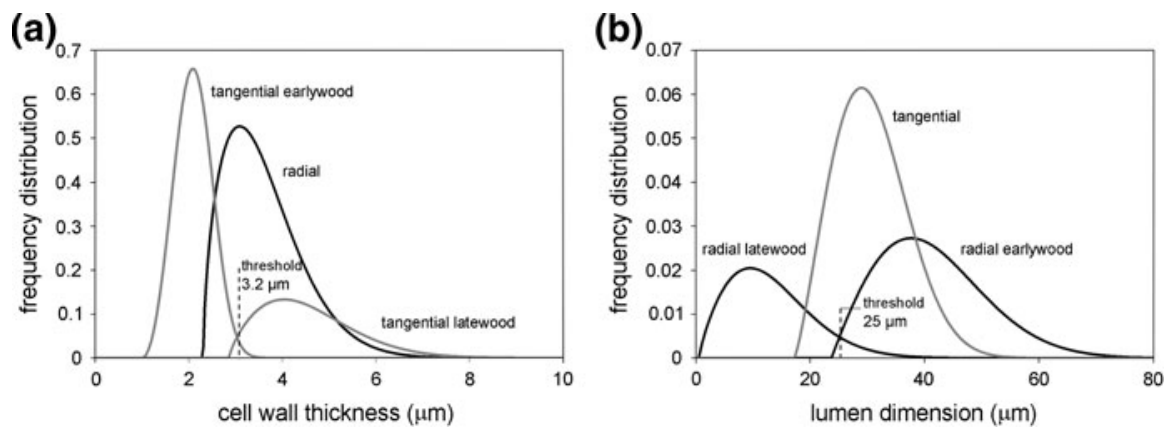

Fig. 4 Graphs of relative frequency distribution, a of the tangential and radial cell wall thickness, $t_{T}$ and $t_{R} ; \mathbf{b}$ of the tangential and radial lumen dimension, $L_{R}$ and $L_{T}$

Table 1 Average cell wall dimensions and lumen dimensions in radial and tangential directions

\begin{tabular}{lllllll}
\hline & $\begin{array}{l}\text { Mean value } \\
(\mathrm{SD}) \\
\mu \mathrm{m} / \mu \mathrm{m}^{2}\end{array}$ & $\begin{array}{l}\text { Earlywood } \\
\text { Mean value } \\
(\mathrm{SD}) \\
\mu \mathrm{m} / \mu \mathrm{m}^{2}\end{array}$ & $\begin{array}{l}\text { Latewood } \\
\text { Mean value } \\
(\mathrm{SD}) \\
\mu \mathrm{m} / \mu \mathrm{m}^{2}\end{array}$ & $\begin{array}{l}\text { Threshold } \\
\mu \mathrm{m}\end{array}$ & $\begin{array}{l}\text { \% of Earlywood } \\
\text { cells above } \\
\text { threshold }\end{array}$ & $\begin{array}{l}\text { \% of Latewood } \\
\text { cells below } \\
\text { threshold }\end{array}$ \\
\hline$t_{R}$ & $3.6(0.8)$ & - & - & - & - & - \\
$t_{T}$ & - & $2.1(0.4)$ & $4.4(1.1)$ & 3.2 & 5.3 & 2.1 \\
$L_{R}$ & - & $40.6(9.8)$ & $12.1(6.5)$ & 25 & 3.6 & 3.1 \\
$L_{T}$ & $30.4(6.4)$ & - & - & - & - & - \\
Lumen area & - & $1,056(328)$ & $254(157)$ & - & - & - \\
\hline
\end{tabular}

cell wall for latewood $(6.23 \mu \mathrm{m})$, although his earlywood radial cell wall thickness of $3.52 \mu \mathrm{m}$ is also very close to the measurement in this study.

Based on the bimodal distribution of the cell wall thickness in tangential direction, a threshold value of the cell wall thickness between earlywood and latewood can be determined. The threshold value is taken as the cell wall thickness found at the minimum in the bimodal distribution between the two modes for earlywood and latewood. The threshold value equals $3.2 \mu \mathrm{m}$.

\section{Lumen dimensions}

Figure 3c, d gives the lumen dimension in radial and tangential directions as a function of the normalized ring position. The radial lumen dimension $L_{R}$ shows first a gradual decrease over the earlywood layer with important scatter, followed by an even more important decrease in the latewood layer showing less scatter. The lumen dimension in the tangential direction is almost constant throughout the year, with a slight decrease in the latewood layer. Less scatter is observed.

Looking at the frequency distributions of the lumen dimension in radial direction (Fig. 4b), a bimodal distribution is observed, with the first skewed mode representing latewood with a mean of $12.1 \mu \mathrm{m}$ and the second symmetric mode 
for earlywood with a mean of $40.6 \mu \mathrm{m}$. The relative frequency distribution for tangential direction shows a unimodal distribution with a mean value of $30.4 \mu \mathrm{m}$, which seems not to be affected by the bimodal distribution of the cell wall thickness variation in the tangential direction.

The average measurements in this study are very close to those reported by Fengel (1969 cited in Brändström 2001), with radial tracheid diameter of $13.1 \mu \mathrm{m}$ for latewood and $39.3 \mu \mathrm{m}$ for earlywood. Also, for the tangential direction, Fengel found similar results with tracheid diameter of $32.7 \mu \mathrm{m}$ for earlywood and $32.1 \mu \mathrm{m}$ for latewood, indicating also a unimodal distribution.

The unimodal distribution of the lumen in tangential direction can be explained by the fact that cells are generated from the same mother cell in the cambium. In tangential direction, the dimension of the lumen remains therefore quite constant over the total growth ring layer. The results of this study confirm also the known trend that the average dimension of the lumen in radial direction is larger than the dimension in tangential direction for earlywood and smaller in the latewood.

Based on the bimodal distribution of the lumen dimension in radial direction, a threshold value of lumen dimension between earlywood and latewood can be determined. The threshold value is taken as the lumen dimension found at the minimum in the bimodal distribution between the two modes for earlywood and latewood. The threshold value equals $25 \mu \mathrm{m}$.

\section{Size of earlywood and latewood layer}

Threshold values for the cell wall thickness in tangential direction at $3.2 \mu \mathrm{m}$ and for the lumen dimension in radial direction at $25 \mu \mathrm{m}$ (Fig. 4) were found. From the relative frequencies of cell dimensions below and above these threshold values across the growth ring for both dimensions, a relative ring position of 0.8 gives a good separation between earlywood and latewood. To control this value, the amount of earlywood and latewood cells that exceed the threshold is determined as found in Table 1. For tangential cell wall thickness, $5.3 \%$ of the earlywood cells and $2.1 \%$ of the latewood cells exceed the threshold of $3.2 \mu \mathrm{m}$. For the lumen dimension in the radial direction, $3.6 \%$ of the earlywood cells and $3.1 \%$ of the latewood cells exceed this limit. The low percentages confirm that the relative ring position of 0.8 can be considered as the limit between earlywood and latewood.

\section{Cell porosity}

The 2-dimensional cell porosity $\phi_{0}$ in the transverse plane is defined as the ratio between lumen area and total cell area. The cell porosity is normally based on the ratio of lumen volume versus total cell volume, but a 2-dimensional approach is allowed due to the large cell dimensions in longitudinal direction compared to radial and tangential directions. It is also noted that, in this cell porosity parameter, the porosity of the cell walls is not considered. The cell is further simplified to a rectangle with cell wall thickness and lumen dimensions as determined above. The aspect ratio's $\alpha_{R}$ and $\alpha_{T}$ is defined as 


$$
\alpha_{R}=\frac{2 t_{R}}{2 t_{R}+L_{R}}, \quad \alpha_{T}=\frac{2 t_{T}}{2 t_{T}+L_{T}}
$$

It is easily proven that

$$
1-\alpha_{R}=\frac{L_{R}}{2 t_{R}+L_{R}}, \quad 1-\alpha_{T}=\frac{L_{T}}{2 t_{T}+L_{T}}
$$

It results that the $2 \mathrm{D}$ cell porosity $\phi_{0}$ is given by

$$
\varphi_{0}=\left(1-\alpha_{R}\right)\left(1-\alpha_{T}\right)
$$

Figure 5 shows the cell porosity as a function of the normalized ring position. The cell porosity is almost constant for the first half part of earlywood and decreases slightly in the second part of the earlywood. Across the latewood, porosity decreases significantly, approaching values as low as $10 \%$. The decrease in porosity is mostly caused by the reduction in the lumen dimension in radial direction and secondly due to the increase in wall thickness in tangential direction.

\section{Discussion}

The variation of the cell dimensions over a growth ring highlights the geometrical impact of the varying conditions during a growth season, with earlywood needed for the important spring sap flow and the latewood contributing to the structural resistance of the tree. This is clearly exemplified by looking at the porosity, which remains quite constant in the earlywood but strongly decreases in the latewood leading to higher wood density. The radial lumen dimension shows a strong reduction over the growth ring and a bimodal distribution, whereas the tangential dimension stays almost constant with a unimodal distribution. Regarding the cell wall, its thickness in the radial direction stays almost constant and thus has a

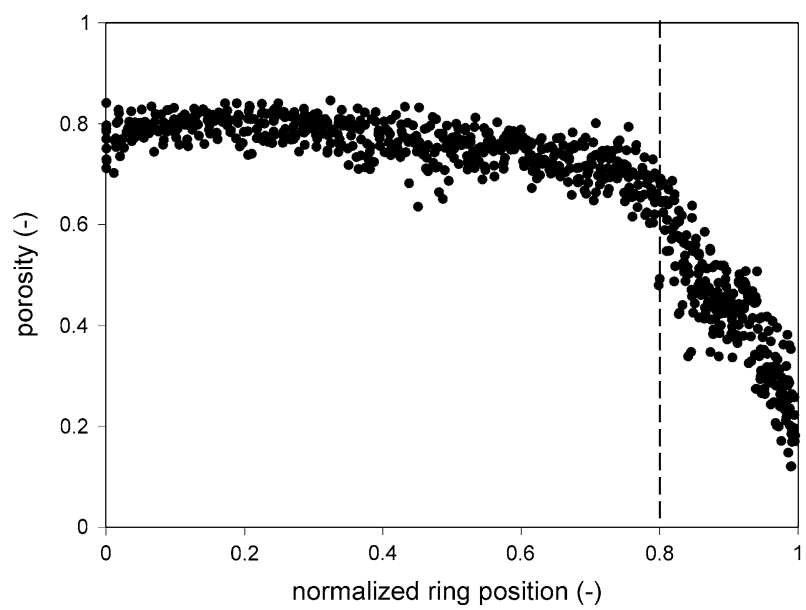

Fig. 5 Calculated porosity versus normalized ring position, with the earlywood-latewood boundary indicated by a dashed line 
unimodal distribution, while in the tangential direction, the cell wall thickness increases strongly in the latewood layer and shows a bimodal distribution.

Figure 6 relates the two dimensions exhibiting the highest variation across the growth ring, namely the tangential cell wall thickness and the radial lumen dimension. The earlywood cells are clustered at the bottom of the graph, showing a quite constant tangential cell wall thickness, while the radial lumen dimension varies between 80 and $20 \mu \mathrm{m}$. In latewood, the cluster is situated to the left, where the cell lumen dimension further decreases from 20 to $2 \mu \mathrm{m}$, while the cell wall thickness increases from 2 to more than $8 \mu \mathrm{m}$ with growth time. The correlation coefficient $\mathrm{R}^{2}$ between the two dimensional parameters is quite low for earlywood $\left(R^{2}=0.0724\right)$, but, although low, higher for latewood $\left(R^{2}=0.1969\right)$. This means that the cells in earlywood adjust with time in spring mainly by reducing their lumen dimension in radial direction (see inset in Fig. 6). The cells in latewood adjust with time later in the growth season mainly by thickening the cell wall in tangential direction and further reducing the lumen dimension in radial direction (see inset in Fig. 6).

Finally, it is noted that the average values of the cell dimensions found in this analysis coincide with the average cell dimensions reported in literature, indicating that the studied growth ring is, on average, representative.

\section{Application example: cell water vapor permeability determined from cell dimensions}

Water vapor transport in the cell in radial direction is described by Fick's law:

$$
g_{R}=-\delta_{R} \frac{\partial p_{v}}{\partial x_{R}}, \quad \delta_{R}=\frac{\delta_{a}}{\mu_{R}}
$$

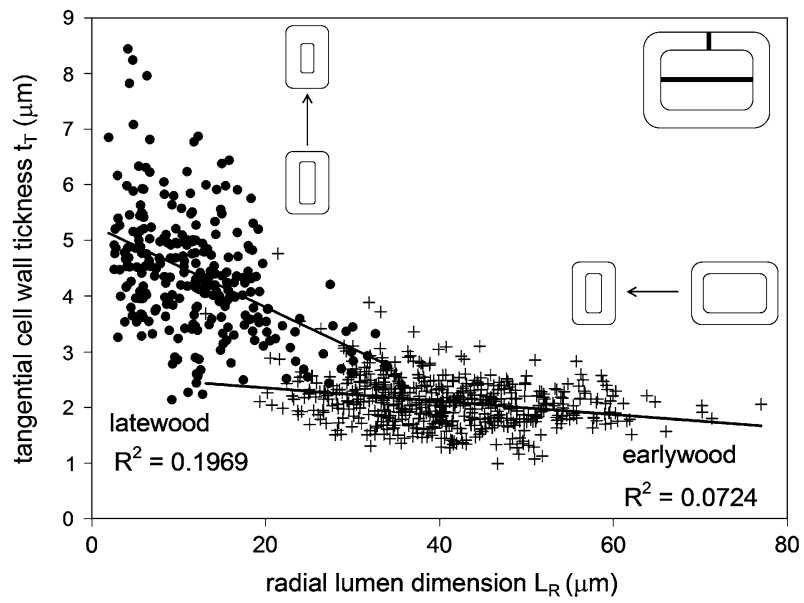

Fig. 6 Plot of cell wall thickness in the tangential direction, $t_{T}$, versus the lumen dimension in the radial direction, $L_{R}$. The earlywood cells are shown with crosses, and latewood with black dots 
with $\mathrm{g}$ the water vapor density flow rate, $p_{v}$ the water vapor pressure, $\delta$ the vapor permeability, $x$ is the spatial coordinate, and $\delta_{a}$ the vapor permeability for dry stagnant air. For clarity reason, also the water vapor resistance factor $\mu$ is introduced, which expresses how much more the material is vapor tight compared with stagnant air. Equation 5 also holds for the tangential direction, by interchanging the subscript $R$ (radial) to $T$.

The vapor permeability of the cell is determined, following Siau (1984), by a parallel-serial resistance combination of cell walls and air in the lumen. Due to the large cell dimensions in longitudinal direction compared with radial and tangential directions, this 2-dimensional approach is allowed for determining the vapor permeability in the radial and tangential directions. Based on the parallel-serial resistance scheme for a cell, the vapor permeability for the cell in radial direction is given by

$$
\delta_{\text {cell }, R}=\alpha_{T} \delta_{\text {wall }}+\frac{1-\alpha_{T}}{\frac{\alpha_{R}}{\delta_{\text {wall }}}+\frac{1-\alpha_{R}}{\delta_{a}}}
$$

with $\delta_{\text {wall }}$ the water vapor permeability of the cell wall and $\delta_{a}$ the vapor permeability of the lumen, considered to be stagnant air. The vapor permeability for the cell in tangential direction can be found by interchanging the subscript $R$ to $T$. It is important to note that the vapor permeability of the cell wall was assumed to be isotropic, which can be justified by the similar chemical composition of the cell wall in the two directions. Further, due to the fact that most bordered pits in spruce are aspirated (closed) and, when non-aspirated, that the pit microstructure limits vapor diffusion (Wadsö, 1993; Krabbenhoft 2003), pits were assumed here to have the same vapor permeability as the cell walls.

Due to the presence of the lumen space filled with stagnant air, which shows very high water vapor permeability compared to the cell wall, the global vapor permeability of the cell will increase. Consequently, the vapor resistance factor of the cell will be lower than the vapor resistance factor of the cell wall. The relative water vapor resistance factor is defined as the ratio between the cell and cell wall vapor resistance factor:

$$
m_{R}=\frac{\mu_{\mathrm{cell}, R}}{\mu_{\mathrm{wall}}}=\frac{1}{\alpha_{T}+\frac{1-\alpha_{T}}{\alpha_{R}+\frac{1-\alpha_{R}}{\mu_{\mathrm{wall}}}}}
$$

with $m_{R}$ the relative $\mu$ factor in radial direction. The reduction factor for the cell in tangential direction can be found by interchanging the subscript $R$ to $T$. The ratio $m$ can be interpreted as a measure for the reduction in the water vapor resistance of the cell due to the presence of air in the lumen. The equation shows that the relative resistance factor depends on the aspects ratio's $\alpha_{R}$ and $\alpha_{T}$ in both directions. It is further noted that the relative vapor resistance factor $m$ depends on the water vapor resistance factor of the wall $\mu_{\text {wall }}$, which depends also on relative humidity. This study is limited to the case of low relative humidity $(<40 \%)$, where it was found that the $m$-factor does not vary a lot with RH, and swelling is not considered. In this study, a water vapor resistance factor for the cell wall of $\mu_{\text {wall }}=2,040$ taken from Zillig (2009) was used. 
Figure $7 \mathrm{a}$ gives the relative vapor resistance factor $m$ for radial and tangential directions as a function of the relative ring position. A high $m$-factor means a high cell vapor resistance or low cell vapor permeability. The trend of the $m$-factor is comparable for both directions, but the $m$-factor is slightly lower for tangential than for radial direction, indicating that the cell is more permeable in tangential than in radial direction. In earlywood, a very low $m$-factor is observed, while in latewood, the $m$-factor increases strongly. The cell is thus vapor open in earlywood, and the vapor permeability decreases strongly in latewood. The decrease in vapor permeability in radial direction is mainly due to a decrease in the lumen dimension in this direction, while the decrease in tangential direction is mainly caused by the increase in cell wall thickness in this direction. As a result, the relative frequency distributions of the $m$-factors are bimodal for both the radial and the tangential directions, as shown in Fig. $7 b$.

Finally, the relationship of the relative vapor resistance factor $m$ versus porosity for each cell is plotted, as shown in Fig. 8. The $m$-factor in radial direction decreases with porosity in an almost linear manner, while for tangential direction, the relation is slightly non-linear, showing more scatter.

From experiments, it is known that the macroscopic vapor permeability of wood is normally higher in radial than in tangential direction, which is opposite to the trend found for the cell permeability. This observation is even more remarkable noting that, in radial direction, the layers of more vapor open earlywood (low resistance) and more vapor tight latewood (high resistance) are in a serial junction, while, in tangential direction, the earlywood and latewood layers are combined in a parallel arrangement. This means that wood will be more vapor permeable in tangential direction than in radial direction. It is however generally known that rays oriented in radial direction can highly contribute to vapor permeability. Therefore, the average cell geometry of the rays in the radial direction is also determined based on optical microscope images in the radial-longitudinal plane. The images are taken at two different locations containing a ray bundle. The total number of ray lumens

(a)

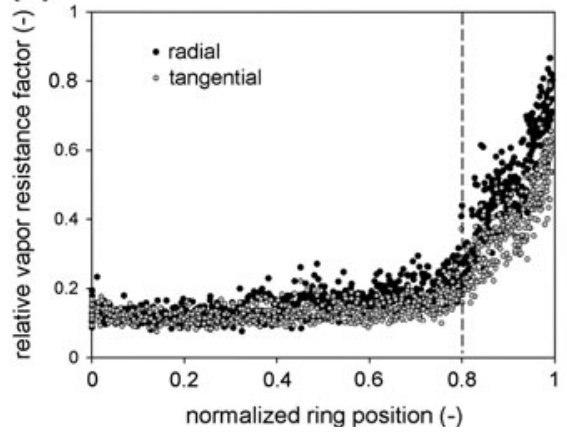

(b)

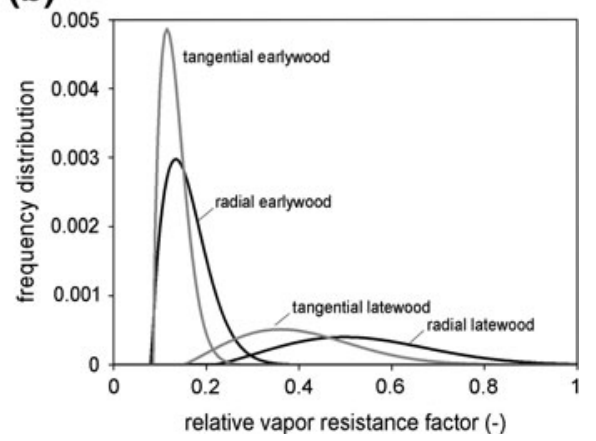

Fig. 7 a Calculated relative water vapor resistance factor for transport in the radial and tangential directions, $m_{R}$ and $m_{T}$, versus normalized ring position, with the earlywood-latewood boundary indicated by a dashed line; $\mathbf{b}$ relative frequency distribution of the tangential and radial reduction in water vapor resistance factor, $m_{R}$ and $m_{T}$ 


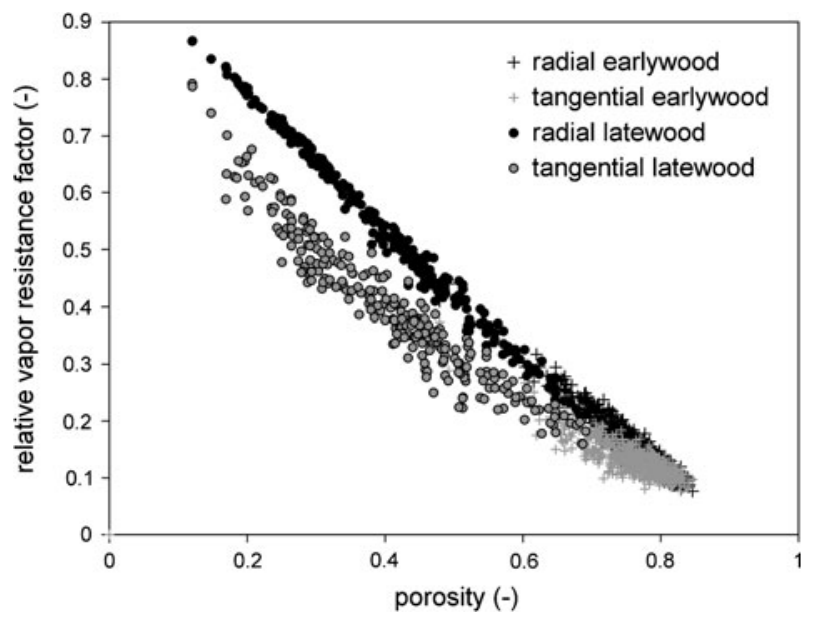

Fig. 8 Calculated results for the relative water vapor resistance factor in radial and tangential directions versus porosity

measured is 143 . The length of the lumen in the radial direction is found to vary greatly. The average length of the lumen of the rays is $190 \mu \mathrm{m}$ (with a standard deviation is $109 \mu \mathrm{m}$ ). The thickness of the cross walls between the rays is found to be almost constant and equal to $0.68 \mu \mathrm{m}$. The average length of the lumen of the ray in tangential direction is $1.8 \mu \mathrm{m}$ with a wall thickness of $1.6 \mu \mathrm{m}$. Using Eq. 7, it is then found that a relative vapor resistance factor, $m_{R}$, equals 0.02 for the rays in radial direction. This very low value of $m_{R}$ means that rays are very vapor open and can be considered as pathways for the transport of vapor allowing vapor to bypass in part the more vapor tight latewood layers. This leads to the conclusion that rays play an important role in the macroscopic vapor permeability of wood in radial direction. A similar investigation into the role of the different pit types on vapor permeability could also provide nice insights but has not been performed so far.

\section{Conclusion}

The measurements presented in this paper differentiating the cell wall thickness and lumen dimensions in the radial and tangential directions have highlighted the high variations of the cell geometry within one single growth ring. As the tangential cell wall thickness and the radial lumen dimension exhibit a bimodal distribution, where each mode can be attributed to earlywood or latewood, the limit between earlywood and latewood cells can also be identified and is found to be equal, for the sample of this study, to 0.8 of the growth ring width. The tracheid dimensions can be used to study the variation of the material properties, like porosity and water vapor permeability over the growth ring. A strong correlation between cell porosity and cell vapor permeability is found. The bimodal frequency distributions of the tangential cell wall thickness and the radial lumen dimension provide an 
explanation for the bimodal frequency distribution of the cell water vapor permeability both in radial and in tangential directions. Finally, based on the prediction of the water vapor permeability of the cells in radial and tangential directions, the high importance of rays on the macroscopic vapor permeability of wood in radial direction can be deduced.

The paper demonstrates how a complete dataset can be used to predict material properties. Also, it shows that the statistical analysis of the dataset provides information on unimodality or bimodality of the distribution of the cell dimensions and threshold values to determine the proportion of earlywood and latewood. Such parameters can be useful in other types of computational studies, using such enriched synthetic cell dimensions.

Acknowledgments The authors are grateful for the financial support of the Swiss National Science Foundation (SNF) under Grant No. 125184.

\section{References}

Badel E, Perré P (2003) Predicting oak wood properties using X-ray inspection: representation, homogenization and localization part II computation of macroscopic properties and microscopic stress fields. Ann For Sci 60:247-257

Badel E, Perré P (2007) The shrinkage of oak predicted from its anatomical pattern: validation of a cognitive model. Trees 21:111-120

Brändström J (2001) Micro- and ultrastructural aspects of Norway spruce tracheids: a review. IAWA J 22:333-353

Eder M, Jungnikl K, Burgert I (2009) A close-up view of wood structure and properties across a growth ring of Norway spruce (Picea abies [L] Karst). Trees 23:79-84

Hofstetter K, Hellmich C, Eberhardsteiner J (2005) Development and experimental validation of a continuum micromechanics model for wood. Eur J Mech A Solid 24:1030-1053

Holmberg S, Persson K, Petersson H (1999) Nonlinear mechanical behavior and analysis of wood and fibre materials. Comput Struct 72:459-480

Krabbenhoft K (2003) Moisture transport in wood A study of physical-mathematical models and their numerical implementation. PhD thesis, Technical University of Denmark, Copenhagen, Denmark

Qing H, Mishnaevsky L (2009) 3D hierarchical computational model of wood as a cellular material with fibril reinforced, heterogeneous multiple layers. Mech Mater 41:1034-1049

Reme PA, Helle T (2002) Assessment of transverse dimensions of wood tracheids using SEM and image analysis. Holz Roh Werkst 60:277-282

Sarén M-P, Serimaa R, Andersson S, Paakkari T, Saranpää P, Pesonen E (2001) Structural variation of tracheids in Norway spruce (Picea abies [L] Karst). J of Struct Biol 136:101-109

Siau JF (1984) Transport processes in wood. Springer, Berlin

Wadsö L (1993) Studies of water vapor transport and sorption in wood. PhD thesis, Lund University, Lund, Sweden

Zillig W (2009) Moisture transport in wood using a multiscale approach PhD thesis. Katholieke Universiteit Leuven, Leuven, Belgium 